\title{
Effect of Quenching Conditions on the Microstructure and Mechanical Properties of 51CrV4 Spring Steel
}

\author{
Lin Zhang ${ }^{1, * \mathbb{D}}$, Dehai Gong ${ }^{2}$, Yunchao Li ${ }^{1}$, Xiaojun Wang ${ }^{2}$, Xixi Ren ${ }^{1}$ and Engang Wang ${ }^{1, *}$ \\ 1 Key Laboratory of Electromagnetic Processing of Materials (Ministry of Education), Northeastern University, \\ Wenhua Road, Shenyang 110819, China; liyunchaoneu@163.com (Y.L.); 13081428815@sina.cn (X.R.) \\ 2 CRRC Guiyang Co., LTD., Dulaying Road, Guiyang 550017, China; dahai_2014@126.com (D.G.); \\ wxjchly@163.com (X.W.) \\ * Correspondence: zhanglin@epm.neu.edu.cn (L.Z.); egwang@mail.neu.edu.cn (E.W.); \\ Tel.: +86-24-8368-3985 (L.Z.); +86-24-8368-1739 (E.W.)
}

Received: 28 November 2018; Accepted: 11 December 2018; Published: 12 December 2018

\begin{abstract}
CrV} 4$ steel is extensively used in large-size damping springs for trains and vehicles. Quenching conditions play an important role in performance enhancement. The present work investigated the effects of various oil-bath temperatures and out-of-oil temperatures on the microstructure and the mechanical properties of this steel. The morphological examination focused on both the quenched martensite and the tempered troostite. Tensile and hardness tests were carried out to evaluate the mechanical properties. The results showed that a coarsening of the martensite occurred at a high oil-bath temperature. In addition, the size and fraction of bainite islands also increased with the increase of oil-bath temperature. In contrast, the carbide size and the intercarbide spacing both increased with the increase of oil-bath temperature. Thus, the tensile strength and the hardness both decreased with increasing oil-bath temperature in accordance with the Hall-Petch relationship. Correspondingly, the ductility increased as the oil-bath temperature increased. At a relatively high out-of-oil temperature, the martensite underwent an auto-tempering process, which led to the precipitation of many tiny carbide particles in the as-quenched martensite laths. This auto-tempering effect enhanced the width of large-sized carbides and reduced their length in the final microstructure. The intercarbide spacings increased with increasing out-of-oil temperature. As the oil-bath temperature increased, the tensile strength and hardness decreased, and the ductility increased. The fracture morphology was examined to explain the results of mechanical properties.
\end{abstract}

Keywords: 51CrV4; spring steel; quenching; martensite; carbides; strength; hardness

\section{Introduction}

The development of high-speed railway trains imposes rigid requirements on the mechanical properties of coil springs used in freight car bogies. Over the last decades, considerable efforts have been made to develop high-performance spring steels. Most coil springs for railway applications are made of quenched and tempered high-strength steels. Elements such as chromium, manganese, and silicon are added to these steels [1]. 51CrV4 steel has high strength and fatigue performance due to the addition of $\mathrm{Cr}$ and $\mathrm{V}$, which is extensively used in large-size damping springs for trains and vehicles [2].

The recommended properties of spring steel include high ductility and toughness at operating temperatures and good hardenability that provides required mechanical properties even at large dimensions [3]. One way to improve the mechanical properties of spring steel could be achieved through the control of alloy composition $[4,5]$. Thermodynamic calculation was used to identify the effects of element change on the phase fraction and transformation temperature in the soaking 
and tempering process [6]. Thermodynamic calculation can be performed using software such as Thermo-Calc. However, composition adjustment means to change the standard of spring steels, which lack feasibility for spring manufacturers. Steels with a similar chemical composition may behave differently due to various mechanical properties as a consequence of their manufacturing route. The mechanical properties can be improved by effective heat treatment $[7,8]$ and thermomechanical treatment $[1,9]$. Quenching before tempering is a key technique to enhance the mechanical properties of spring steels, in which the final structure is significantly affected by the processing parameters during heat treatment. For this reason, the heat treatment parameters of spring steel are controlled thoroughly by the producers. Large efforts have been made in recent years to investigate the effects of heat treatment parameters during soaking and tempering process [8,10-12], such as the time and temperature of soaking and tempering.

The emphasis in the research of spring steels has been focused on increasing the strength while maintaining good ductility $[6,13]$. One way of improving steel properties is refining its microstructure [14,15], which means to reduce the ferrite grain size, the size of carbides, and the intercarbide spacing. The mechanical behavior of steel is influenced by the inclusions and precipitates, which act as stress raisers [16]. Large inclusions are most harmful to mechanical properties. Fine precipitation can be achieved through microalloying and effective heat treatment [17]. This leads to the enhancement of hardness and strength. Retained austenite is also an important structural component in the spring steel, whose stability is affected by the processing parameters during heat treatment, such as the soaking temperature and the cooling rate [18].

The present work performed soaking, quenching, and tempering on $51 \mathrm{CrV} 4$ steel since this kind of heat treatment is a conventional manufacturing route to improve its mechanical properties. Previous researchers have studied the effects of various parameters during heat treatment on the microstructure and mechanical properties of $51 \mathrm{CrV} 4$ steels [3,19-21]. However, very few researches have focused on the detailed quenching conditions such as the oil-bath temperature and the out-of-oil workpiece temperature, which is essential to obtain the required strength and ductility.

In this work, the heat treatment experiments were carried out on $51 \mathrm{CrV} 4$ steel under various oil-bath temperatures and out-of-oil temperatures. The quenched martensite and tempered troostite were examined. The microstructure of the steel was analyzed by scanning electron microscopy. Effects of the quenching parameters on the mechanical properties were evaluated in terms of tensile strength, elongation, hardness, and fracture. The relationship between the microstructure and the mechanical properties was discussed. The purpose of this work is to obtain a technical reference to control the mechanical properties using the oil-bath temperature and out-of-oil temperature.

\section{Materials and Methods}

$51 \mathrm{CrV} 4$ spring steels have been processed by soaking, quenching, and tempering. Table 1 shows the chemical composition of the commercial $51 \mathrm{CrV} 4$ spring steel used in this work, which was identified by chemical analysis. The original specimens were cut from a hot deformed steel bar. The size of the cylinder specimen was $\varnothing 20 \mathrm{~mm} \times 300 \mathrm{~mm}$. This work performed the heat treatment according to a technology route usually used to fabricate a train damping spring. First, the steel bars were heated to $930^{\circ} \mathrm{C}$ and isothermally held for $30 \mathrm{~min}$ to form austenite with a uniform distribution of the alloying elements. During this soaking process, nitrogen gas was injected into the furnace to protect the steel bars from oxidization. Afterward, the steel bars were quenched into a stirred oil bath which was set at various oil-bath temperatures $\left(20^{\circ} \mathrm{C}, 50^{\circ} \mathrm{C}\right.$, and $\left.80^{\circ} \mathrm{C}\right)$. The cooling rates were estimated to be $34^{\circ} \mathrm{C} / \mathrm{s}$, $30^{\circ} \mathrm{C} / \mathrm{s}$, and $25^{\circ} \mathrm{C} / \mathrm{s}$ respectively. The surface temperature of the workpiece was measured during the quenching process, and the workpieces were taken out of the oil bath at various temperatures $\left(60^{\circ} \mathrm{C}\right.$, $90^{\circ} \mathrm{C}$, and $\left.120^{\circ} \mathrm{C}\right)$, which was defined as the out-of-oil temperature in this paper. After quenching, the workpieces were cooled in the air to room temperature (about $15^{\circ} \mathrm{C}$ ). Next, the specimens were tempered at $450{ }^{\circ} \mathrm{C}$ for $90 \mathrm{~min}$. After tempering, the samples were water quenched. 
Table 1. Chemical composition of the as-received 51CrV4 steel (mass percent, \%).

\begin{tabular}{cccccccccccc}
\hline $\mathbf{C}$ & $\mathbf{S i}$ & $\mathbf{M n}$ & $\mathbf{S}$ & $\mathbf{P}$ & $\mathbf{C r}$ & $\mathbf{N i}$ & $\mathbf{C u}$ & $\mathbf{V}$ & Al & Mo & Fe \\
\hline 0.546 & 0.229 & 0.951 & 0.004 & 0.014 & 1.08 & 0.051 & 0.106 & 0.168 & 0.017 & 0.006 & balance \\
\hline
\end{tabular}

Each bar was subsequently sectioned and etched to reveal the microstructure. The microstructure was observed using an Ultra Plus field emission scanning electron microscope (Carl Zeiss AG, Oberkochen, Germany). Image-Pro Plus software (Version 6.0, Media Cybernetics, Inc., Rockville, MD, USA) was used to analyze the size and the area fraction of phases. The phases were identified by the X-ray diffraction analysis using a Philips X'Pert Pro MPD diffractometer (PANalytical Co., Almelo, The Netherlands). In order to evaluate the mechanical properties of the samples, tensile testing and hardness testing were performed. Hardness measurements were taken from a polished but unetched sample, using a Rockwell apparatus (Shenyang Kejing Auto-instrument Co., LTD, Shenyang, China), with a load of $150 \mathrm{~kg}$ and loading time of $5 \mathrm{~s}$. Tensile testing was performed in a Shimadzu AG-X $100 \mathrm{kN}$ testing machine (Shimadzu Corp., Kyoto, Japan) in accordance with the requirements and recommendations of the ISO 6892-1:2011 [22]. The round bone-shaped tensile testing specimens were prepared by lathe. The tensile testing specimen had an overall length of $150 \mathrm{~mm}$, a gauge length of $50 \mathrm{~mm}$, and a diameter of $6 \mathrm{~mm}$. An extensometer was set during test to measure the strain precisely. The strain rate was about $2.3 \times 10^{-5} \cdot \mathrm{s}^{-1}$.

\section{Results and Discussion}

Figure 1a shows the microstructure of as-received commercial $51 \mathrm{CrV} 4$ steel used in this work. The microstructure of the as-received steel appeared to be spheroidite, in which many spherical carbides were distributed dispersedly in the ferrite grains. The XRD patterns of the as-received, quenched, and tempered specimens were analyzed. The XRD result of as-received steel showed a main phase of $\alpha$-Fe (Figure 1b), which is the matrix of the microstructure shown in Figure 1a. The carbides had a small X-ray reflection and showed no peaks in the XRD result. Figure $1 \mathrm{~b}-\mathrm{d}$ shows the XRD patterns of specimens which were quenched at various oil-bath temperatures and out-of-oil temperatures. The quenched specimens showed a pattern of martensite, which appeared to have peak positions similar to the $\alpha$-Fe phase. The pattern of quenched specimens in Figure $1 b, c$ included the peaks of $\gamma$-Fe phase, indicating that retained austenite existed in the two specimens quenched at an out-of-oil temperature of $90^{\circ} \mathrm{C}$. In the two patterns of the tempered specimens that corresponded to the quenched specimens respectively, the lower peaks of $\gamma$-Fe phase indicated that the fraction of retained austenite decreased (Figure $1 \mathrm{~b}, \mathrm{c}$ ). The patterns of $80^{\circ} \mathrm{C}$ oil-bath temperature had a higher (200) peak of $\gamma$-Fe phase compared with that of $50{ }^{\circ} \mathrm{C}$ oil-bath temperature (Figure $1 \mathrm{~b}, \mathrm{c}$ ), indicating that high oil-bath temperature enhances the fraction of retained austenite. On the contrary, the high out-of-oil temperature reduced the fraction of retained austenite. The quenched and tempered specimens at $120^{\circ} \mathrm{C}$ out-of-oil temperature appeared to have no $\gamma$-Fe peaks in the pattern (Figure 1d). 

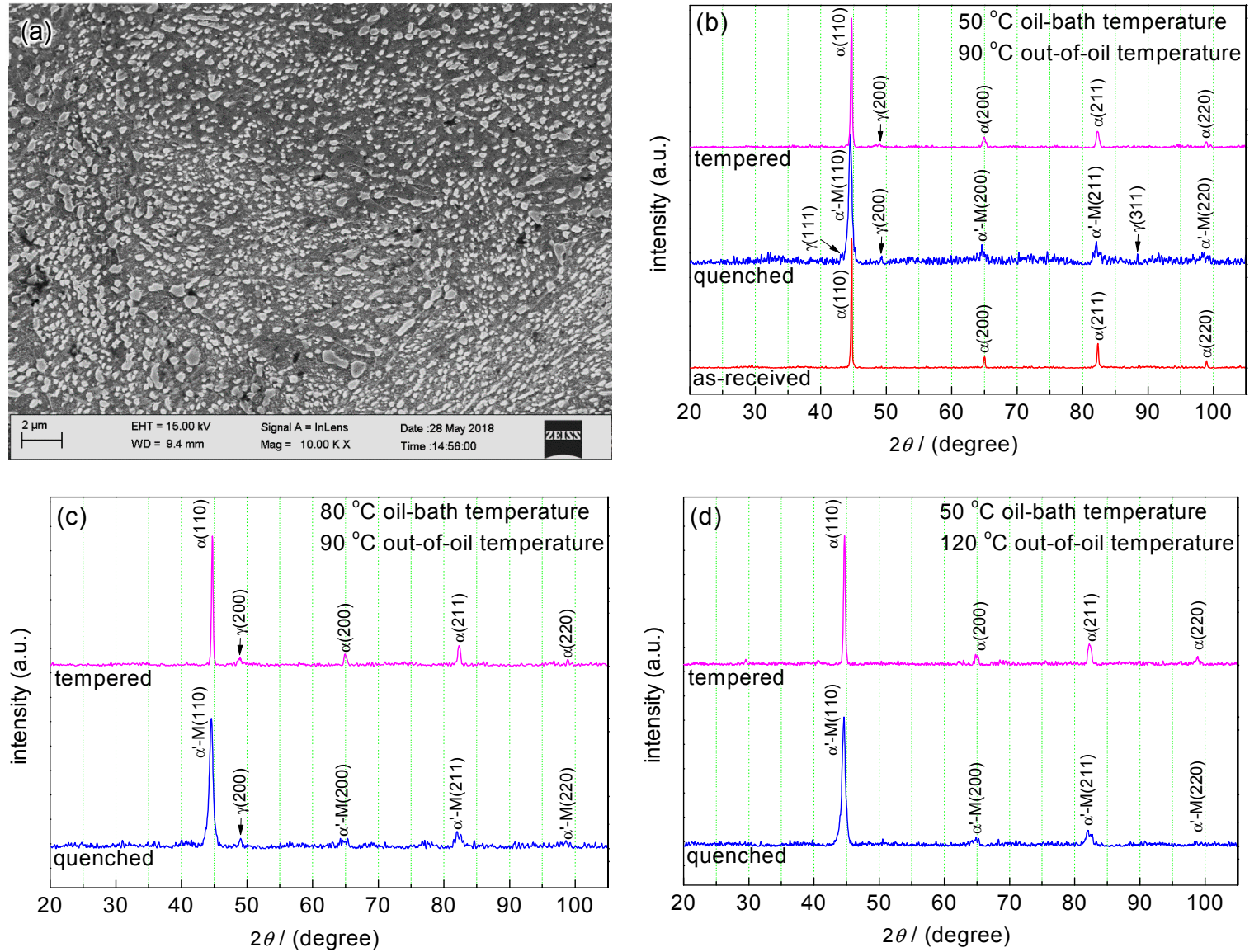

Figure 1. Microstructure of as-received 51CrV4 steel bar and X-ray diffraction (XRD) patterns of as-received, quenched, and tempered specimens: (a) microstructure of as-received steel; (b) XRD patterns of the as-received steel, quenched and tempered specimens at $50{ }^{\circ} \mathrm{C}$ oil-bath temperature and $90{ }^{\circ} \mathrm{C}$ out-of-oil temperature; (c) XRD patterns of specimens at $80^{\circ} \mathrm{C}$ oil-bath temperature and $90{ }^{\circ} \mathrm{C}$ out-of-oil temperature; (d) XRD patterns of specimens at $50{ }^{\circ} \mathrm{C}$ oil-bath temperature and $120^{\circ} \mathrm{C}$ out-of-oil temperature.

Figure $2 \mathrm{a}, \mathrm{c}, \mathrm{e}$ presents the microstructure of steel bars after quenching at various oil-bath temperatures of $20^{\circ} \mathrm{C}, 50^{\circ} \mathrm{C}$, and $80^{\circ} \mathrm{C}$ respectively (The out-of-oil temperature was $90{ }^{\circ} \mathrm{C}$ ). In the as-quenched condition, the microstructure consisted of untempered martensite, bainite, and retained austenite. The retained austenite was identified by the XRD results, whereas it was not profound in the structure of Figure 2. The needle-like martensite lath was the main component of the quenched structure, accompanied by a few large-sized martensite laths. The martensite laths were apparently coarser under higher oil-bath temperature. The athermal transformation from austenite to martensite is dependent only on the amount of undercooling below the $M_{\mathrm{S}}$ temperature $(\Delta T)$. The volume fraction of martensite increases with increasing $\Delta T$ [23]. The number of martensite nuclei also increases with the increase of undercooling prior to transformation [24]. The final grain size of the martensite will be finer as the number of nuclei is larger. Quenching at a lower oil-bath temperature tends to achieve higher undercooling. Therefore, martensite tends to be finer as the oil-bath temperature decreases. 

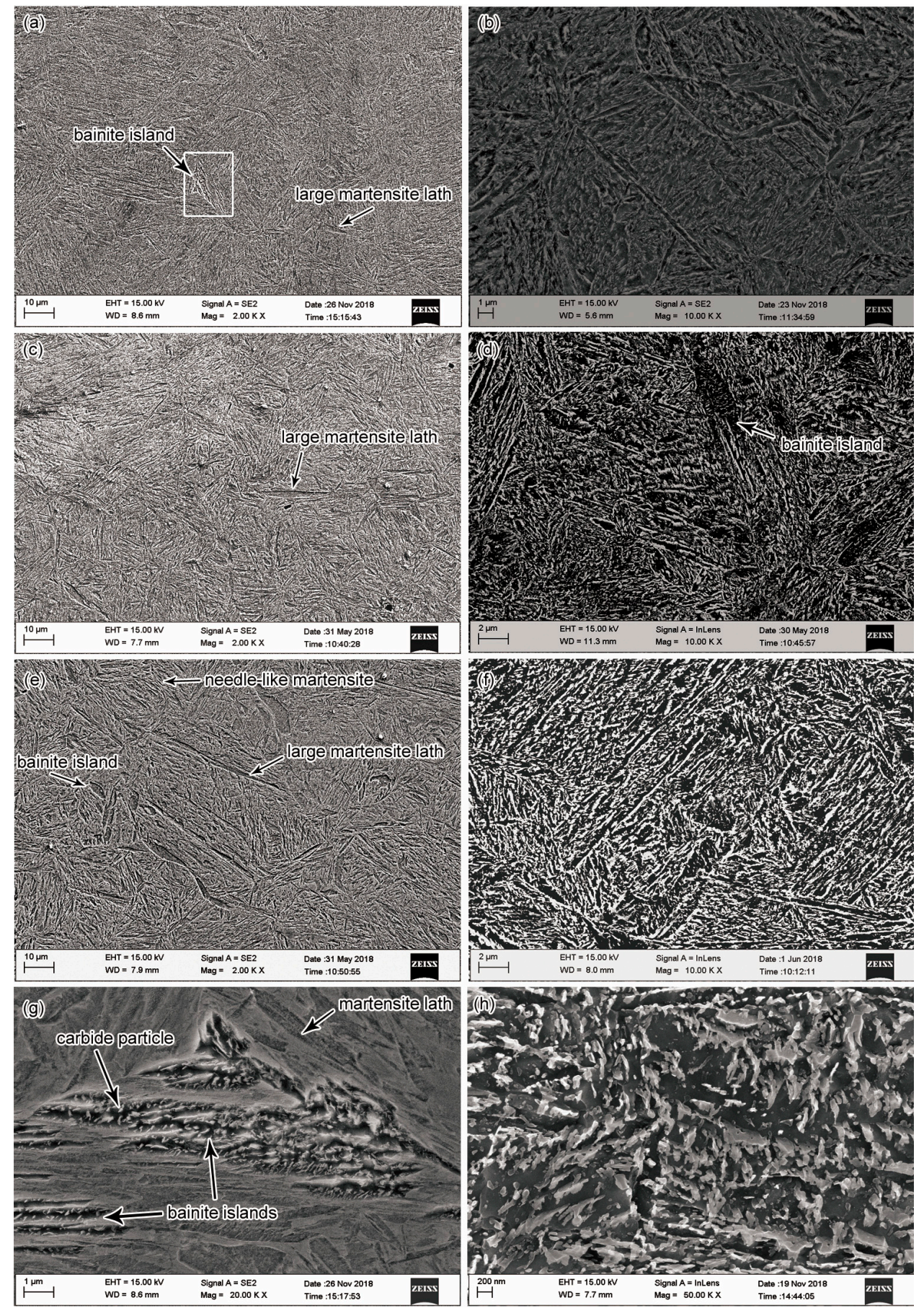

Figure 2. Microstructure of the steel bars: Specimens quenched at oil-bath temperatures of $20^{\circ} \mathrm{C}(\mathrm{a})$, $50{ }^{\circ} \mathrm{C}$, (c) and $80^{\circ} \mathrm{C}(\mathbf{e})$ respectively; (b), (d), and (f) are the tempered microstructures corresponding to specimens of (a), (c), (e) respectively; (g) shows a higher-magnification view of a bainite island in the area outlined by a rectangle in (a); (h) shows a morphology of carbide precipitation of higher magnification in the same specimen of $(\mathbf{d})$.

The quenched structure contained lens-shaped bainite islands, as shown in Figure 2a,c,e,g. There were carbide particles precipitated in the bainite islands (Figure 2g). A similar morphology has been analyzed by Sencic et al. to be considered as bainite grains [3]. Gao et al. also observed this kind of islands in the martensite matrix and described it as bainite islands [25]. The size and fraction of the bainite islands increased with the increase of oil-bath temperature. At various oil-bath 
temperatures, the cooling rate of quenching was different. Thus, the diffusion distance of carbon atoms was varied and the $\gamma \rightarrow \alpha$ transition velocity was also changed. Besides, bainite formation is much slower than martensite because it requires diffusion. Therefore, the low oil-bath temperature prevented carbon atom diffusion, delaying the bainite transformation and reducing the size of bainite islands. Taken together, these results suggest that the formation of martensite and bainite islands were both influenced by the oil-bath temperature.

In the tempering process, the martensite and retained austenite decomposed, leading to the precipitation of carbides. The formation of fairly fine carbides was shown in Figure $2 b, d, f$. The tempered structure appeared to be troostite, in which the prior martensite laths were replaced by ferrite grains. It can be seen that the microstructure of all the three specimens contained long carbides. The long carbides were accompanied by a certain number of short carbide particles (Figure $2 \mathrm{~h}$ ). The carbides were located mainly at prior interlath boundaries, although some carbide particles distributed inside the prior martensite lath. The length and width of the carbides both increased with the increase of oil-bath temperatures. Correspondingly, the intercarbide spacings also increased. At oil-bath temperatures of 20,50 , and $80^{\circ} \mathrm{C}$, the average intercarbide spacings were measured to be $0.184,0.212$, and $0.242 \mu \mathrm{m}$ respectively.

Carbides can easily nucleate at dislocations due to a stronger enrichment of carbon. In the tempering process of a quenched steel bar, the carbides appeared to precipitate along the grain boundaries and the interphase boundaries between martensite and other phases [26-28]. Therefore, small martensite laths with more boundaries tend to prepare more locations for the nucleation of carbides. Jang et al. found that the carbides precipitated along the surfaces of the martensite phase, and the carbides have smaller size and were more widely dispersed due to the smaller width of martensite phase [29]. As discussed above, the size of martensite laths decreased with the decrease of oil-bath temperature in this work, thus the number of precipitated carbides tended to increase due to more interfaces or boundaries in the microstructure. Correspondingly, the carbides tended to have a smaller size. On the contrary, the number of precipitated carbides decreased and the carbides tended to have a larger size with the increase of oil-bath temperature.

The bainite islands were also observed in the tempered microstructure (Figure 2d), which has a similar lens-shaped morphology to those in the quenched sample.

The temperature of workpieces decreased with an increase in submerged time during the quenching process. The surface temperatures of the steel bars were measured when they were taken out of the oil bath (out-of-oil temperature) to identify its effects on the microstructures. Figure $3 a, c, e$ present the microstructures of steel bars quenching at various out-of-oil temperatures of $60^{\circ} \mathrm{C}, 90^{\circ} \mathrm{C}$, and $120^{\circ} \mathrm{C}$ respectively (The oil-bath temperature was $50^{\circ} \mathrm{C}$ ). Martensite was the main phase in the microstructures of all the three conditions. Both large-sized martensite laths and slim needle-like martensite existed in the microstructure. There was no significant discrepancy in the size of martensite laths in the specimens at various out-of-oil temperatures. Whereas, a high out-of-oil temperature of $120^{\circ} \mathrm{C}$ enhanced the chance of auto-tempering in the microstructure, which led to the precipitation of many tiny carbide particles in the as-quenched martensite crystals (Figure $3 \mathrm{~h}$ ). In contrast, the carbide precipitation was not observed in the specimen at a low out-of-oil temperature such as $60^{\circ} \mathrm{C}$ (Figure $3 \mathrm{~g}$ ), indicating that the auto-tempering was inhibited. The auto-tempering was more profound in the large-sized martensite lath. Morsdorf et al. found that the coarse martensite lath has a higher density of carbide particles compared to the thinner laths, which is due to the high degree of auto-tempering and lower dislocation density in the coarse laths [30]. 

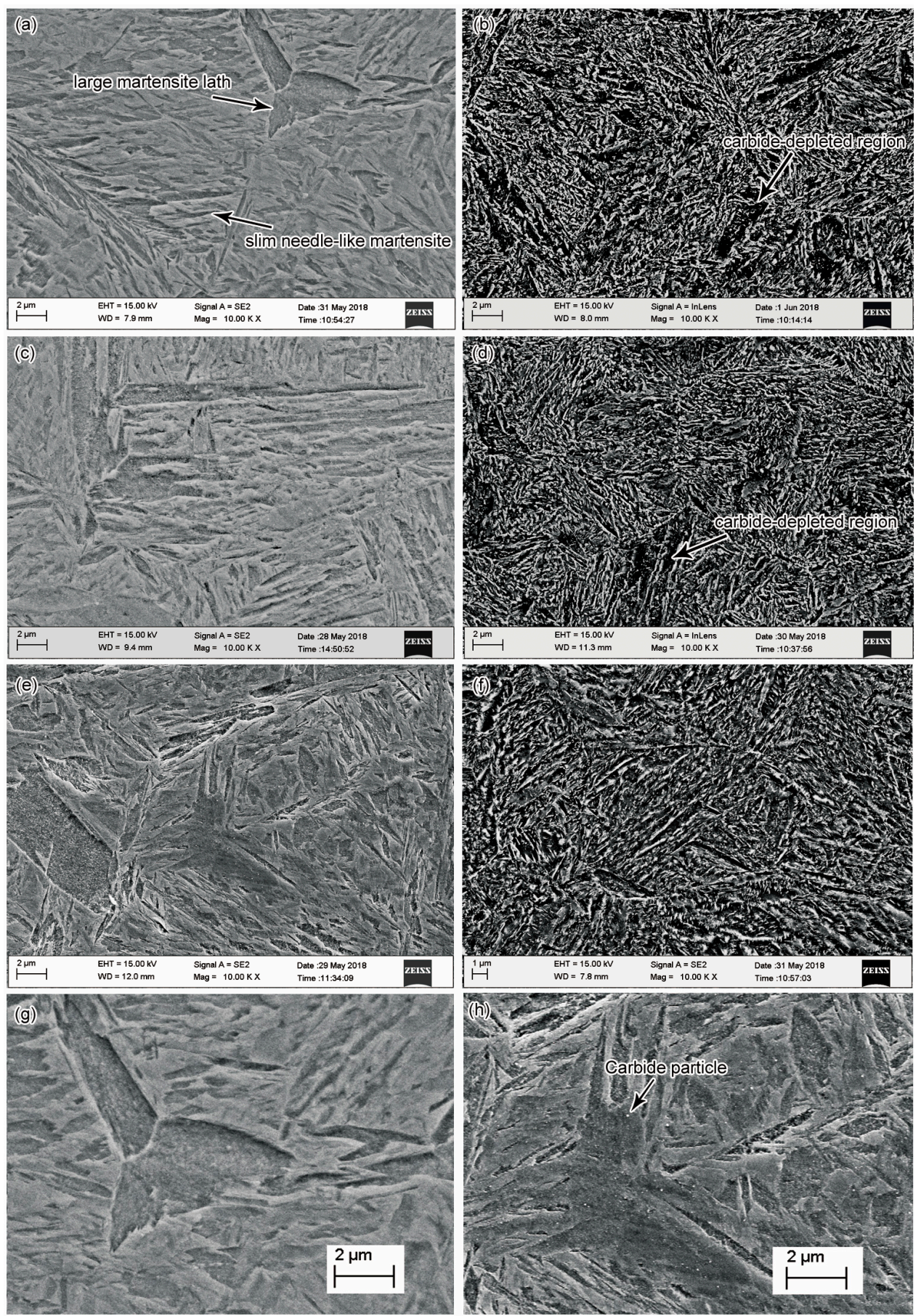

Figure 3. Microstructure of the steel bars: Specimens quenched at various out-of-oil temperatures of $60^{\circ} \mathrm{C}(\mathbf{a}), 90^{\circ} \mathrm{C}(\mathbf{b})$, and $120^{\circ} \mathrm{C}$ (c) respectively; (b), (d), and (f) are the tempered microstructures corresponding to the specimens of (a), (c), (e) respectively; (g) and (h) show the martensite morphology of higher magnification in the specimens of (a) and (e), respectively.

Figure $3 b, d, f$ shows the tempered microstructures corresponding to the quenched specimens in Figure 3a,c,e respectively. The microstructure contained long carbides accompanied by a certain number of short carbide particles. The carbide distribution appeared to be different in the tempered microstructures at various out-of-oil temperatures. There were carbide-depleted regions (large black regions) in the microstructure where the distribution of carbide was sparser than other regions. The area of the carbide-depleted regions appeared to decrease with the increase of out-of-oil temperature. 
These carbide-depleted regions might correspond to the large-sized martensite laths in the quenched specimens. As discussed above, carbides prefer to precipitate along the lath boundary, and only a few carbide particles tended to precipitate inside the large-sized martensite lath at a low out-of-oil temperature. The martensite underwent an auto-tempering process at a relatively high out-of-oil temperature, and carbide particles could nucleate inside the large martensite laths during the auto-tempering process (Figure $3 \mathrm{~h}$ ). This provided an opportunity for them to grow into larger carbides in the subsequent principal tempering process, leading to the increase of final number density of carbides, especially in the carbide-depleted region. Therefore, the carbide-depleted regions were not profound in the specimen at a high out-of-oil temperature such as $120^{\circ} \mathrm{C}$ (Figure $3 \mathrm{f}$ ), and the distribution of carbides appeared to be more homogeneous than that at a lower out-of-oil temperature. However, the carbide size increased with the increase of out-of-oil temperature. Correspondingly, the intercarbide spacings also increased. At out-of-oil temperatures of 60,90 , and $120^{\circ} \mathrm{C}$, the average widths of the intercarbide spacing were measured to be $0.177,0.222$, and $0.231 \mu \mathrm{m}$ respectively.

Figure 4 shows the size distribution of tempered carbides in the steel bars at various out-of-oil temperatures (The statistical area in the microstructure was $600 \mathrm{~m}^{2}$ ). The number density of small carbides (with a length smaller than $0.4 \mu \mathrm{m}$ ) increased considerably as the out-of-oil temperature increased from $60^{\circ} \mathrm{C}$ to a higher degree of $90{ }^{\circ} \mathrm{C}$ or $120^{\circ} \mathrm{C}$. This was caused by the auto-tempering effect discussed above. The lowest number density of small carbides was observed in the specimen at out-of-oil temperature of $60^{\circ} \mathrm{C}$, when the auto-tempering has not taken effect. A relatively high out-of-oil temperature tended to increase the width of large-sized carbides (with a width larger than $0.24 \mu \mathrm{m}$ ). However, the length of large-sized carbides (with a length larger than $1.2 \mu \mathrm{m}$ ) tended to decrease with the increase of out-of-oil temperature. This effect indicates that the fraction of long carbides decreased, and the particle-shaped carbides tended to have a higher fraction as the out-of-oil temperature increased. As discussed above, the carbides nucleated inside large martensite laths as tiny particles during an auto-tempering process, which reduced their chance to grow into long carbides in the later principal tempering process, thus the fraction of particle-shaped carbides increased.
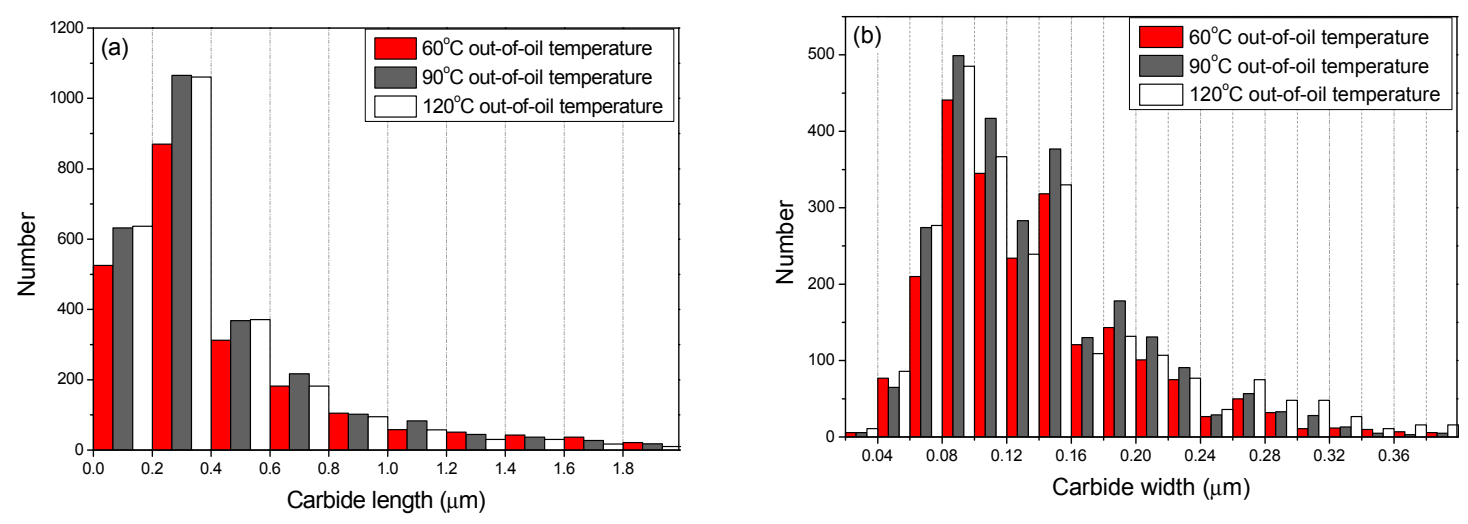

Figure 4. The carbide length (a) and width (b) distribution in the tempered steel bars quenched at various out-of-oil temperatures of $60^{\circ} \mathrm{C}, 90^{\circ} \mathrm{C}$, and $120^{\circ} \mathrm{C}$ respectively.

The phase diagram of 51CrV4 steel was shown in Figure 5, which was calculated based on the Thermo-Calc software. The composition of $51 \mathrm{CrV} 4$ steel was close to the eutectoid point. The $A_{1}$ temperature was about $743{ }^{\circ} \mathrm{C}$. There were several kinds of precipitations formed at various temperatures, including the $\mathrm{MnS}$, the cementite, the $\mathrm{M}_{7} \mathrm{C}_{3}$ (carbide of $\mathrm{Fe}$ and $\mathrm{Cr}$ ), the graphite, the $\mathrm{M}_{2} \mathrm{P}$ (phosphide of $\mathrm{Fe}$ and $\mathrm{Mn}$ ), and the $\mathrm{M}_{3} \mathrm{C}_{2}$ (carbide of Fe and $\mathrm{Cr}$ ). At the tempering temperature of this work, the $\mathrm{M}_{7} \mathrm{C}_{3}$-type carbides were precipitated. Moreover, $\mathrm{MnS}$ existed as inclusions at both soaking and tempering process. Graphite is predicted to precipitate below $600{ }^{\circ} \mathrm{C}$ in the phase diagram. However, graphite was not observed in the microstructure of this work. 


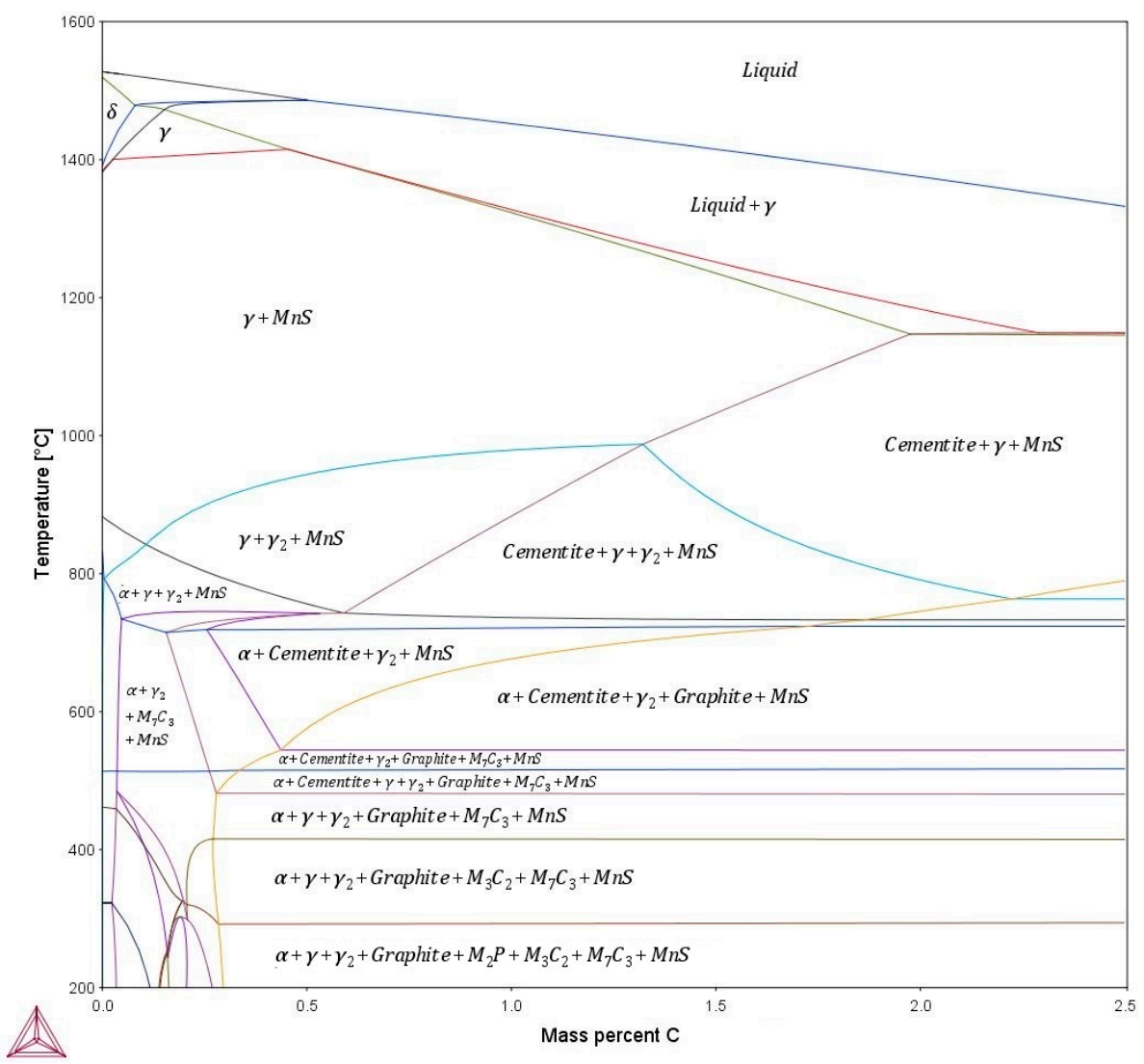

Figure 5. Phase diagram of 51CrV4 spring steel (calculated based on the Thermo-Calc software).

Figure 6 shows the mole fraction of precipitated phases changing with temperature, which was calculated using Thermo-Calc software. There are several kinds of carbide precipitations occurring below $740{ }^{\circ} \mathrm{C}$, including the cementite, the $\mathrm{M}_{3} \mathrm{C}_{2}$-type, and the $\mathrm{M}_{7} \mathrm{C}_{3}$-type carbides. A significant amount of cementite is stable in the temperature range of $590-720^{\circ} \mathrm{C}$, whereas it rapidly decreases with decreasing temperature below $590^{\circ} \mathrm{C}$. The cementite is completely replaced by $\mathrm{M}_{3} \mathrm{C}_{2}$-type and $\mathrm{M}_{7} \mathrm{C}_{3}$-type carbides. $\mathrm{M}_{7} \mathrm{C}_{3}$ carbide reaches its largest fraction and remains stable in the temperature range of $420-480{ }^{\circ} \mathrm{C}$, which covers the tempering temperature of this work, indicating that the carbides observed in Figures 2 and 3 were mostly $M_{7} C_{3}$-type. The amount of $M_{7} C_{3}$ carbide is gradually reduced and replaced by $\mathrm{M}_{3} \mathrm{C}_{2}$ carbides below $420^{\circ} \mathrm{C}$.

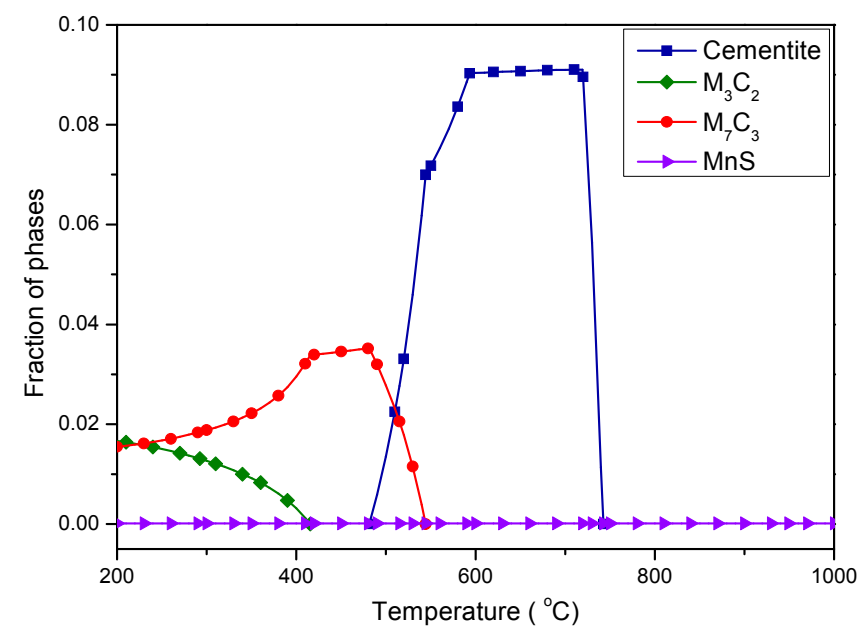

Figure 6. The mole fraction of precipitated phases at various temperatures (calculated based on the Thermo-Calc software) 
As indicated by the phase diagram (Figure 5), the MnS inclusions could exist in a large temperature range below $1400^{\circ} \mathrm{C}$. Figure $7 \mathrm{a}, \mathrm{b}$ shows the morphology of several MnS inclusion particles, which was identified by EDS elemental mapping and point analysis. Figure 7c shows the corresponding EDS elemental mapping images of the inclusions in Figure 7a, which indicate that the main elements of the inclusions were Mn and S. Figure $7 \mathrm{~d}$ shows the EDS point analysis of point 1 in the inclusion of Figure $7 \mathrm{~b}$. The composition appeared to be $40 \% \mathrm{Mn}$ and $42 \% \mathrm{~S}$, indicating that the inclusion was MnS.
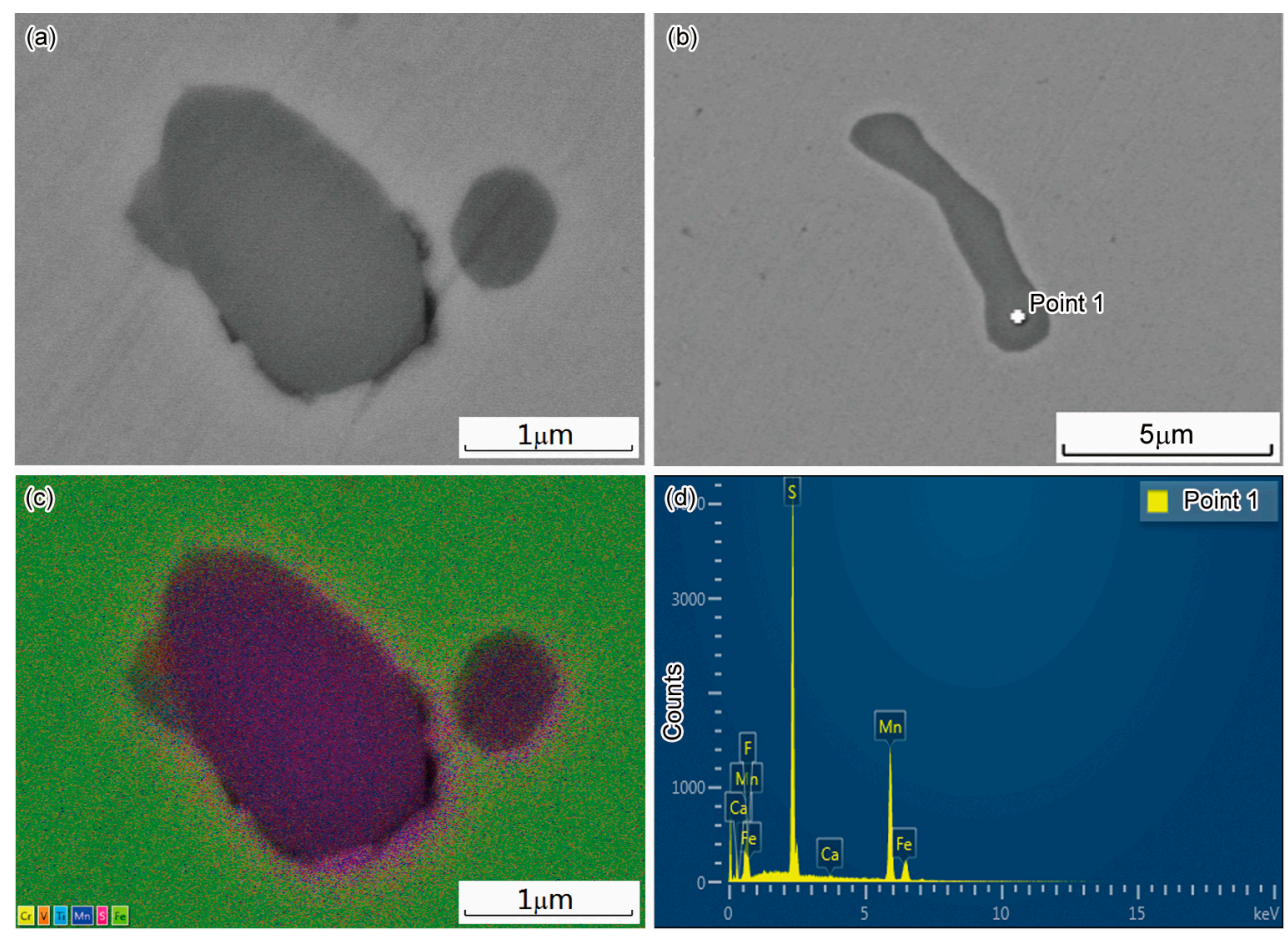

Figure 7. MnS Inclusion particles: (a,b) SEM image of two inclusion particles; (c) EDS elemental mapping around the inclusions of (a); (d) EDS point analysis of point 1.

The mechanical properties of tempered steel bars were directly influenced by the intercarbide spacing. The troostite belongs to the pearlite-type structure. The strength of the pearlite-type structure (ferrite + carbide) has been reported to follow a Hall-Petch type relationship with respect to the intercarbide spacing [31-34]. Both yield strength and hardness follow a Hall-Petch relationship $[33,35,36]$ :

$$
\begin{aligned}
\sigma_{\mathrm{y}} & =\sigma_{0}+k_{\mathrm{s}} \lambda^{-1 / 2} \\
H_{\mathrm{rc}} & =H_{0}+k_{\mathrm{h}} \lambda^{-1 / 2}
\end{aligned}
$$

where $\lambda$ is the intercarbide spacing, $\sigma_{\mathrm{y}}$ is the yield strength of the steel, $\sigma_{0}$ is the internal frictional strength of ferrite with the infinite mean free path, and $k_{\mathrm{s}}$ is a dislocation locking constant during yielding. $H_{\mathrm{rc}}$ is the Rockwell hardness, $H_{0}$ is the hardness of the ferrite with the infinite mean free path, and $k_{\mathrm{h}}$ is related to the dislocation locking constant during hardness measurement.

Since the intercarbide spacings increased with the increase of oil-bath temperature, the tensile strength and hardness should decrease with the increase of oil-bath temperature according to the Hall-Petch relationship. Figure 8a shows the ultimate tensile strength (UTS) and yield strength (YS) changing with oil-bath temperature, in which the stress and strain were engineering values. As the oil-bath temperature increased from 20 to $80^{\circ} \mathrm{C}$, the average UTS decreased from 1599 to $1549 \mathrm{MPa}$, and the average YS decreased from 1451 to $1398 \mathrm{MPa}$. Correspondingly, the percentages of area reduction and elongation at break both increased with increasing oil-bath temperature, indicating that a high oil-bath temperature benefits the enhancement of ductility. An extensometer was set during 
the tensile test to measure the strain precisely. The elastic modulus was calculated from the slopes of elastic part of the stress-strain curves. The elasticity modulus, which is an important parameter relating to the spring behavior, also decreased with increasing oil-bath temperature, as shown in Figure $8 \mathrm{~b}$. Figure $8 \mathrm{c}$ shows the hardness results tested along a diameter in a cross section of the tempered steel bar. The hardness value showed a small discrepancy between the center and surface, indicating that the steel bar was fully hardened during the quenching process. The hardness of tempered workpieces decreased with the increase of oil-bath temperature. As discussed in Figure 1, the fraction of austenite was higher in samples at $80^{\circ} \mathrm{C}$ oil-bath temperature than that at $50^{\circ} \mathrm{C}$, which also contribute to the decrease of strength and hardness.
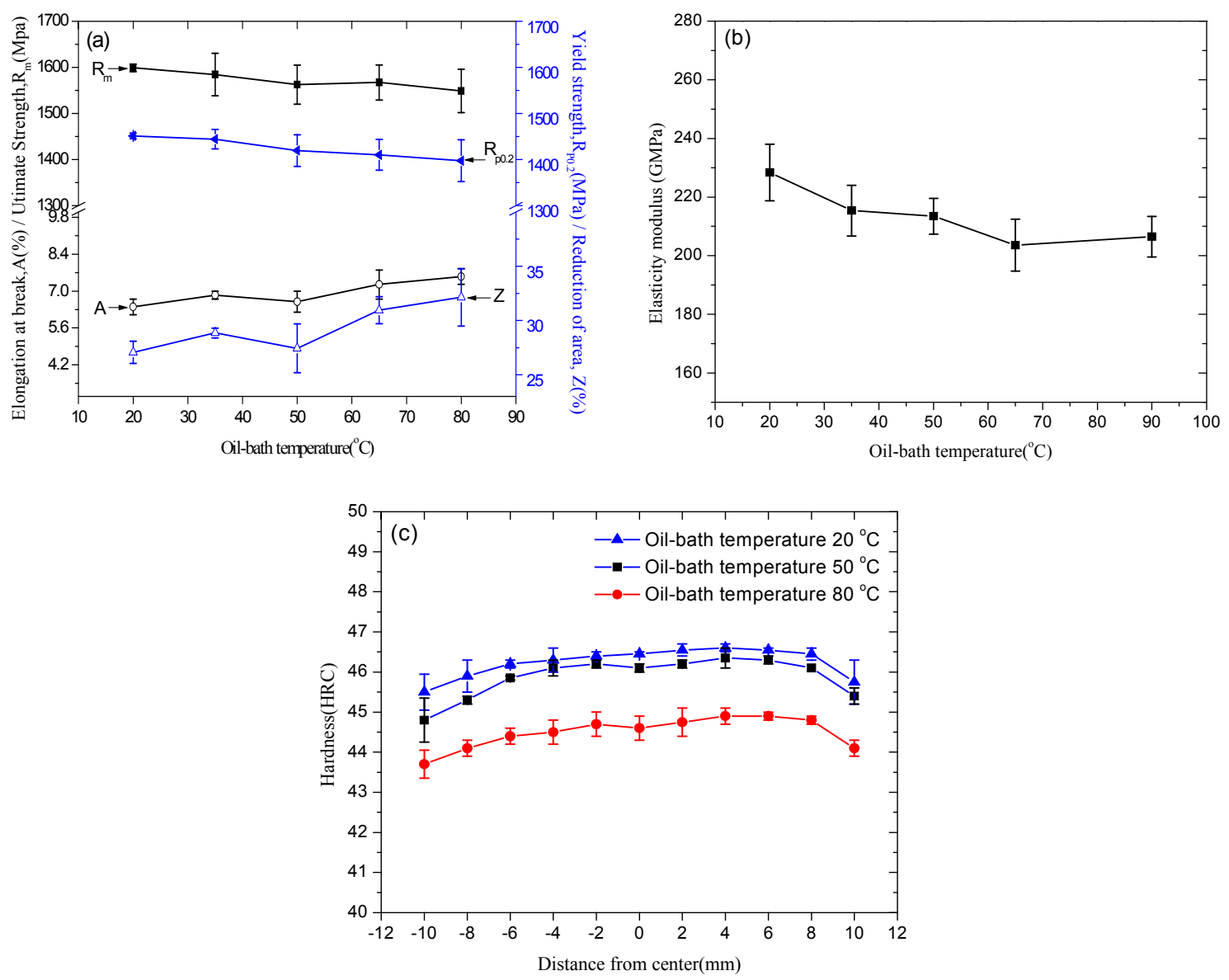

Figure 8. Mechanical properties of the steel bars at various oil-bath temperatures: (a) ultimate tensile strength, yield strength, elongation at break, and reduction of area (The stress and strain are engineering value); (b) elasticity modulus; (c) rockwell hardness (HRC) of tempered samples.

As discussed above, the intercarbide spacings decreased with the increase of out-of-oil temperature. According to the Hall-Petch relation, the tensile strength and hardness should decrease with increasing oil-bath temperature. Figure 9a shows the ultimate tensile strength (UTS) and yield strength (YS) changing with out-of-oil temperature, in which the stress and strain were engineering values. As the out-of-oil temperature increased from 60 to $120^{\circ} \mathrm{C}$, the average UTS decreased from 1615 to $1513 \mathrm{MPa}$, and the average YS decreased from 1461 to $1404 \mathrm{MPa}$. Correspondingly, the percentages of area reduction and elongation at break both increased with the increase of out-of-oil temperature, indicating that a high out-of-oil temperature resulted in the enhancement of ductility. The elasticity modulus also decreased with the increase of out-of-oil temperature, as shown in Figure 9b. 

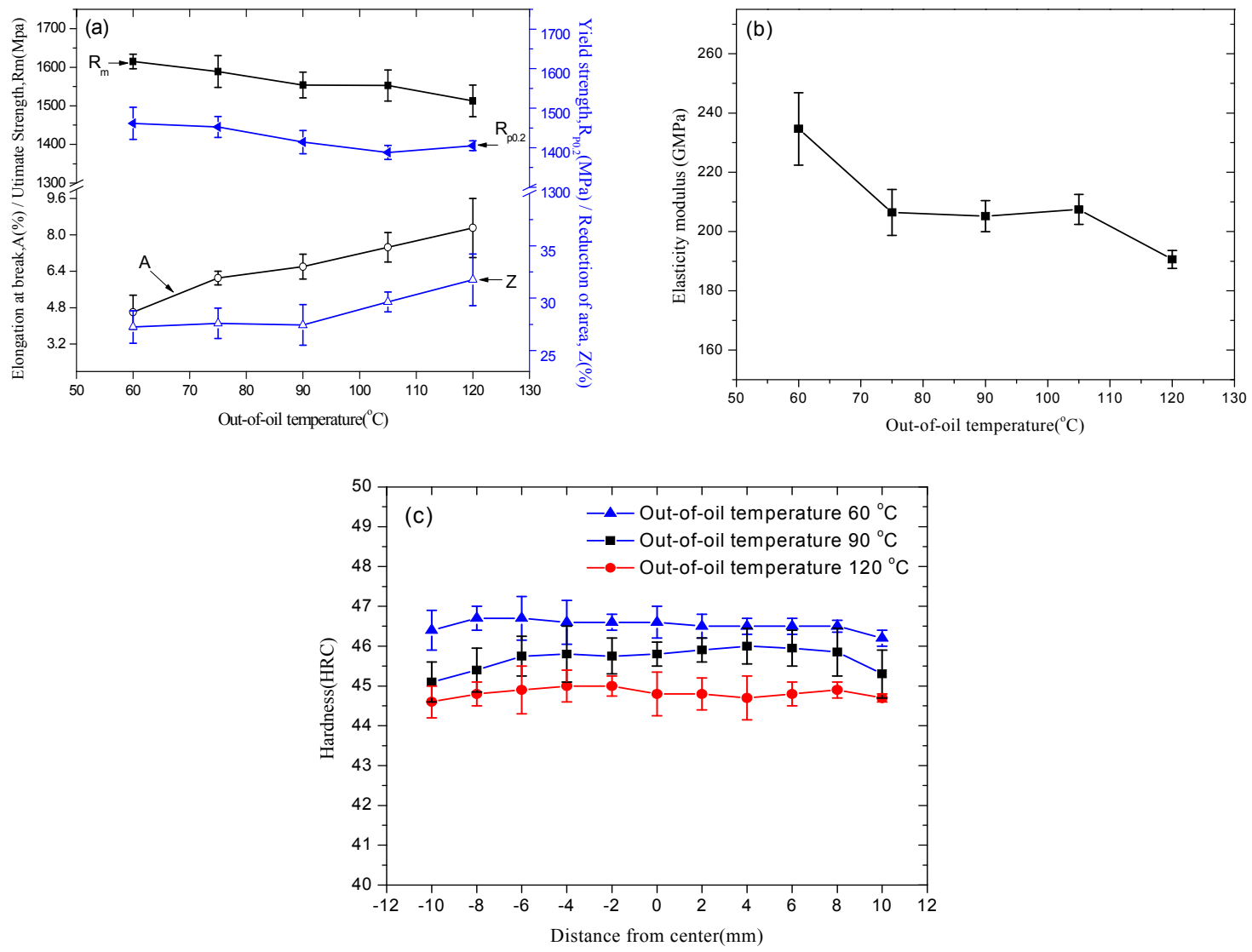

Figure 9. Mechanical properties of the steel bars at various out-of-oil temperatures: (a) ultimate tensile strength, yield strength, elongation at break, and reduction of area (The stress and strain are engineering value); (b) elasticity modulus; (c) rockwell hardness (HRC) of tempered samples.

The auto-tempering was a possible reason to cause the change of mechanical properties at a high out-of-oil temperature. The auto-tempering process generated carbide particles inside the carbide-depleted region at a high out-of-oil temperature (Figure 3), and reduced the volume fraction of such areas in the final microstructure after subsequent principal tempering. Besides, the auto-tempering reduced the length of large-sized carbides and enhanced their width at the same time (Figure 4). This coarsening behavior of the carbides at high out-of-oil temperature contributed to a relative drop of tensile strength.

As the out-of-oil temperature increased, the hardness decreased due to the increase of intercarbide spacing of carbides (Figure 9c). In the tempered specimen quenched at $60^{\circ} \mathrm{C}$ out-of-oil temperature, most of the hardness results were in the range of $46 \sim 47 \mathrm{HRC}$; when the out-of-oil temperature changed to $120{ }^{\circ} \mathrm{C}$, most of the hardness results were in the range of $44 \sim 45 \mathrm{HRC}$, and the decrement was about $4.3 \%$.

The yield strength and hardness of the steel samples with various intercarbide spacings are shown in Figure 10. Two dashed lines are plotted as functions of the inverse of the square root of the intercarbide spacing $\left(\lambda^{-1 / 2}\right)$ in Figure 10a,b respectively. From the plot, intercepts and slopes were calculated, and the following empirical relationships were obtained:

$$
\begin{gathered}
\sigma_{\mathrm{y}}=973+206 \lambda^{-1 / 2} \\
H_{\mathrm{rc}}=34.5+5.1 \lambda^{-1 / 2}
\end{gathered}
$$




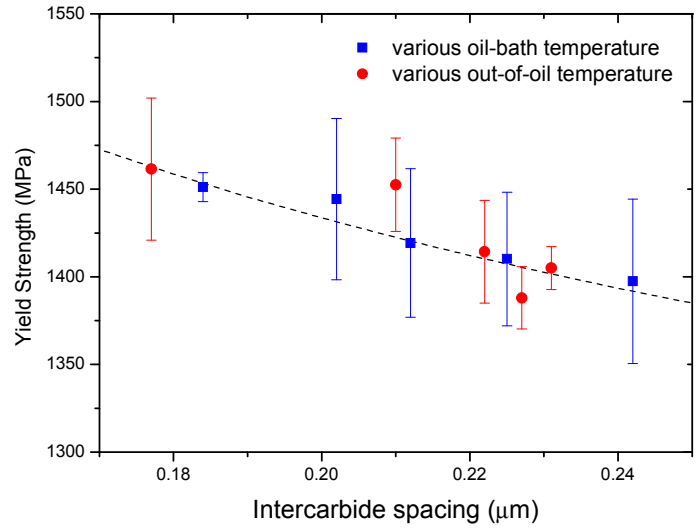

(a)

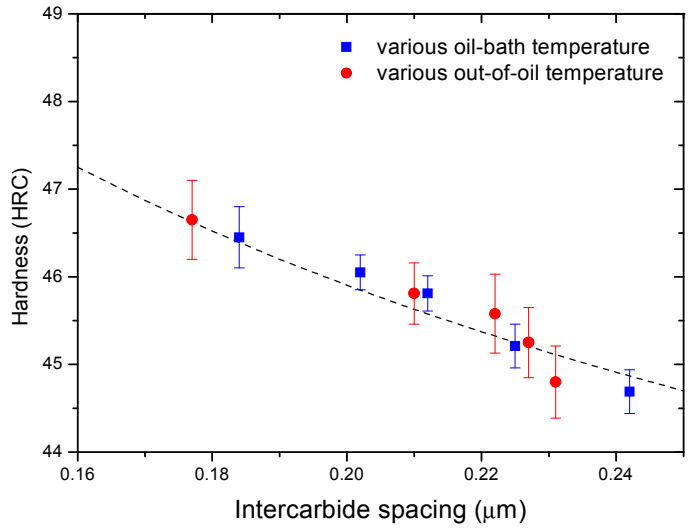

(b)

Figure 10. Yield strength and hardness of the steel bars with various intercarbide spacings: (a) yield strength; (b) hardness.

This implies that the yield strength and the hardness both decreased with increasing intercarbide in accordance with the Hall-Petch relationship. Both high oil-bath temperature and high out-of-oil temperature resulted in an increase in intercarbide spacing, which led to the decrease of strength and hardness.

According to the above discussions on mechanical properties, both high oil-bath temperature and high out-of-oil temperature benefited the enhancement of the ductility, which correspondingly reduced the strength and hardness. These effects were further proved by the fracture analysis. Figure 11 shows the SEM microfractographs of the steel bars investigated. The fractures were uneven and showed random fluctuations. Fractures of all the four conditions were composed by dimple and quasi-cleavage morphology, which indicated the experimental steel had high toughness. Many deep dimples were observed, and many small dimples were distributed around large dimples. There were pockets existing in all the four conditions, which contained features that resemble localized quasi-cleavage. Figure 11a,b presents the fracture morphology of the specimens at 20 and $80^{\circ} \mathrm{C}$ oil-bath temperatures, respectively. The specimen at $80^{\circ} \mathrm{C}$ oil-bath temperature had a larger dimple size, indicating that this specimen had a higher ductility. Figure 11c,d shows the tensile fractures of tempered $51 \mathrm{CrV} 4$ spring steel bars at various out-of-oil temperatures. At $60{ }^{\circ} \mathrm{C}$ out-of-oil temperature, the dimples appearing in the tensile fracture were small and uniformly distributed, most of the dimples had sizes less than $1 \mu \mathrm{m}$. At $120^{\circ} \mathrm{C}$ out-of-oil temperature, many large dimples with sizes larger than $1 \mu \mathrm{m}$ were observed. Therefore, the fracture was more ductile at a higher out-of-oil temperature. The fracture morphology could explain the mechanical property results presented in Figures 8 and 9. It is noted that a fine inclusion was observed in Figure 11d, and the inclusion was MnS compound according to the EDS analysis. 

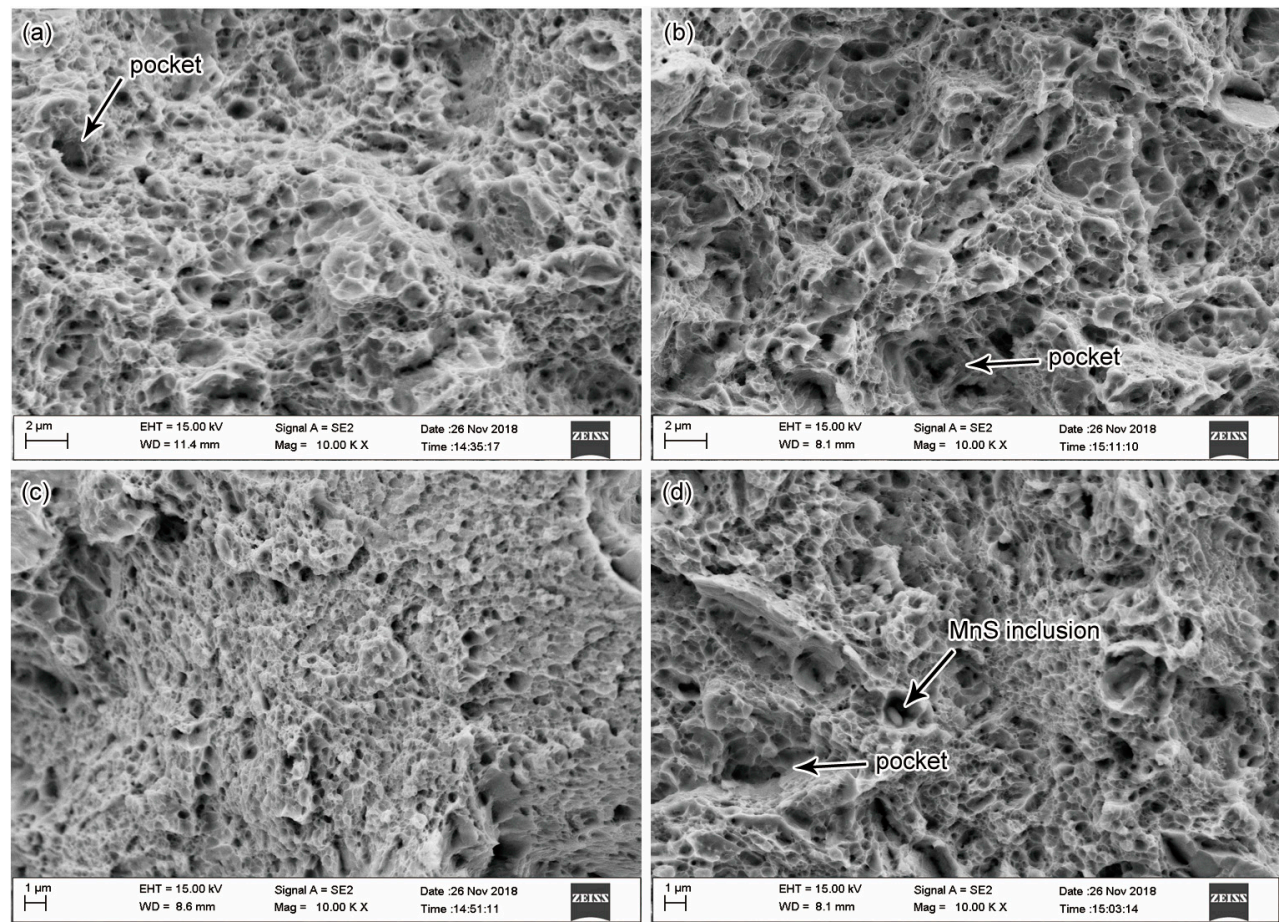

Figure 11. Fracture morphology of tempered steel bars: specimens quenched at oil-bath temperature of $20^{\circ} \mathrm{C}$ (a) and $80^{\circ} \mathrm{C}(\mathbf{b})$, respectively; specimens quenched at out-of-oil temperature of $60^{\circ} \mathrm{C}(\mathbf{c})$ and $120^{\circ} \mathrm{C}(\mathrm{d})$, respectively.

The size of the dimples on the fracture surface was governed by the number and distribution of microvoids that are nucleated at regions of localized strain discontinuity, such as that associated with grain boundaries or second phase particles [37]. The microvoids grew to a large size and led to large dimples when the nucleation sites were few and widely spaced. As discussed above, the average intercarbide spacing increased with both the increase of oil-bath temperature and out-of-oil temperature. The large intercarbide spacing caused a small number density of nucleation sites and resulted in large dimple size.

\section{Conclusions}

The present work performed soaking, quenching, and tempering on $51 \mathrm{CrV} 4$ steel. The effects of various oil-bath temperatures and out-of-oil temperatures on the quenching microstructure, tempering microstructure, and the mechanical properties were investigated, the main conclusions can be summarized as follows:

The as-quenched microstructure of $51 \mathrm{CrV} 4$ steel consisted of needle-like martensite, large-sized martensite laths, lens-shaped bainite islands, and retained austenite. The tempered microstructure contained long carbides, accompanied by a certain number of carbide particles. According to the phase diagram calculated based on Thermo-Calc software, the $\mathrm{M}_{7} \mathrm{C}_{3}$-type carbides were precipitated at the tempering temperature of this work.

A lower oil-bath temperature tended to achieve higher cooling rate and higher undercooling, which led to the finer size of martensite. A coarsening of the martensite occurred at a high oil-bath temperature. In addition, the size and fraction of the bainite islands increased with the increase of oil-bath temperature. In the tempered specimens which have been quenched at a high oil-bath temperature, the number of precipitated carbides decreased and the carbides tended to have a larger size. Since the intercarbide spacings increased with increasing oil-bath temperature, the tensile strength and hardness both decreased with increasing oil-bath temperature in accordance with the Hall-Petch relationship. Correspondingly, the ductility increased with the increase of oil-bath temperature. 
A high out-of-oil temperature enhanced the chance of auto-tempering, which led to the precipitation of tiny carbide particles in the as-quenched martensite laths. This auto-tempering effect reduced the length of large-sized carbides and enhanced their width in the final tempered microstructure. The intercarbide spacings between carbides increased with the increase of out-of-oil temperature. The tensile strength and hardness decreased with increasing oil-bath temperature, and the ductility increased correspondingly.

The fracture of $51 \mathrm{CrV} 4$ steel was composed by dimple and quasi-cleavage morphology. Both a higher oil-bath temperature and a higher out-of-oil temperature resulted in larger dimples, which can explain the enhancement of ductility.

Author Contributions: Methodology, L.Z. and E.W.; Investigation, L.Z. and Y.L.; Formal Analysis, X.R. and D.G.; Data Curation, X.W. and D.G.; Writing-Original Draft Preparation, L.Z.

Funding: This research was funded by the National Natural Science Foundation of China, grant number 51674083, the project of heat treatment optimization and product quality control of springs used in urban rail train (funded by the CRRC Guiyang Co., LTD.), and the Programme of Introducing Talents of Discipline to Universities (the 111 Project of China), grant number B07015.

Conflicts of Interest: The authors declare no conflict of interest.

\section{References}

1. Ardehali, B.A.; Ponge, D.; Raabe, D. Refinement of grain boundary carbides in a Si-Cr spring steel by thermomechanical treatment. Mater. Sci. Eng. A 2006, 426, 194-201. [CrossRef]

2. Wang, Z.; Liu, X.; Xie, F.; Lai, C.; Li, H.; Zhang, Q. Dynamic recrystallization behavior and critical strain of 51CrV4 high-strength spring steel during hot deformation. JOM 2018, 70, 2385-2391. [CrossRef]

3. Sencic, B.; Leskovsek, V. Fracture toughness of the vacuum-heat-treated spring steel 51CrV4. Mater. Tehnol. 2011, 45, 67-73.

4. Nam, W.J.; Lee, C.S.; Ban, D.Y. Effects of alloy additions and tempering temperature on the sag resistance of Si-Cr spring steels. Mater. Sci. Eng. A 2000, 289, 8-17. [CrossRef]

5. Zhang, C.L.; Liu, Y.Z.; Jiang, C.; Xiao, J.F. Effects of Niobium and Vanadium on Hydrogen-induced Delayed Fracture in High Strength Spring Steel. J. Iron Steel Res. Int. 2011, 18, 49-53. [CrossRef]

6. Podgornik, B.; Tehovnik, F.; Burja, J.; Seni, B. Effect of modifying the chemical composition on the properties of spring steel. Metall. Mater. Trans. A 2018, 49, 3283-3292. [CrossRef]

7. Ostash, O.P.; Chepil, R.V.; Markashova, L.I.; Hrybovs'ka, V.I.; Kulyk, V.V.; Berdnikova, O.M. Influence of the modes of heat treatment on the durability of springs made of 65G steel. Mater. Sci. 2018, 53, 684-690. [CrossRef]

8. Liu, S.Y.; Liu, D.Y.; Liu, S.C. Effect of heat treatment on fatigue resistance of spring steel 60Si2CrVAT. Met. Sci. Heat Treat. 2010, 52, 57-60.

9. Ai, J.H.; Zhao, T.C.; Gao, H.J.; Hu, Y.H.; Xie, X.S. Effect of controlled rolling and cooling on the microstructure and mechanical properties of 60Si2MnA spring steel rod. J. Mater. Process. Technol. 2005, 160, 390-395. [CrossRef]

10. Harada, Y.; Mori, K. Effect of processing temperature on warm shot peening of spring steel. J. Mater. Process. Technol. 2005, 162, 498-503. [CrossRef]

11. Anil, K.V.; Karthikeyan, M.K.; Gupta, R.K.; Ramkumar, P.; Uday, P.M. Heat treatment studies on 50CrV4 spring steel. Mater. Sci. Forum 2015, 830, 139-142. [CrossRef]

12. Xu, L.; Chen, L.; Sun, W. Effects of soaking and tempering temperature on microstructure and mechanical properties of 65Si2MnWE spring steel. Vacuum 2018, 154, 322-332. [CrossRef]

13. Nie, B.; Zhang, Z.; Zhao, Z.; Zhong, Q. Very high cycle fatigue behavior of shot-peened $3 \mathrm{Cr} 13$ high strength spring steel. Mater. Design 2013, 50, 503-508. [CrossRef]

14. Podgornik, B.; Leskovek, V.; Godec, M.; Sencic, B. Microstructure refinement and its effect on properties of spring steel. Mater. Sci. Eng. A 2014, 599, 81-86. [CrossRef]

15. Luo, Z.F.; Liang, Y.L.; Long, S.L.; Jiang, Y.; Wu, Z.L. Effects of ultra-refine grain and micro-nano twins on mechanical properties of 51CrV4 spring steel. Mater. Sci. Eng. A 2017, 690, 225-232. [CrossRef] 
16. Bytyqi, A.; Jenko, M.; Godec, M. Analysis of inclusions in spring steel using scanning electron microscopy and Auger spectroscopy. Vacuum 2012, 86, 648-651. [CrossRef]

17. Podgornik, B.; Torkar, M.; Burja, J.; Godec, M.; Sencic, B. Improving properties of spring steel through nano-particles alloying. Mater. Sci. Eng. A 2015, 638, 183-189. [CrossRef]

18. Kucerova, L. The effect of two-step heat treatment parameters on microstructure and mechanical properties of 42SiMn steel. Metals 2017, 7,537. [CrossRef]

19. Hauserova, D.; Dlouhy, J.; Kotous, J. Structure refinement of spring steel $51 C$ rv 4 after accelerated spheroidisation. Arch. Metall. Mater. 2017, 62, 1473-1477. [CrossRef]

20. Kubit, A.; Bucior, M.; Zielecki, W.; Stachowicz, F. The Impact of Heat Treatment and Shot Peening on the Fatigue Strength of 51CrV4 Steel. Procedia Struct. Integrity 2016, 2, 3330-3336. [CrossRef]

21. Solic, S.; Sencic, B.; Leskovek, V. Influence of heat treatment on mechanical properties of $51 \mathrm{CrV} 4 \mathrm{high}$ strength spring steel. Int. Heat Treat. Surf. Eng. 2013, 7, 92-98. [CrossRef]

22. International Standard of Metallic Materials-Tensile Testing-Part 1: Method of Test at Room Temperature; ISO 6892-1; International Organization for Standardization (ISO): Geneva, Switzerland, 2011.

23. Krauss, G. Steels Processing, Structure, and Performance, 2nd ed.; ASM International: Materials Park, OH, USA, 2015; pp. 72-74.

24. Porter, D.A.; Easterling, K.E. Phase Transformations in Metals and Alloys, 2nd ed.; Chapman \& Hall: London, UK, 1992; pp. 398-401.

25. Gao, G.; Zhang, H.; Gui, X.; Tan, Z.; Bai, B. Tempering behavior of ductile $1700 \mathrm{MPa}$ Mn-Si-Cr-C steel treated by quenching and partitioning process incorporating bainite formation. J. Mater. Sci. Technol. 2015, 31, 199-204. [CrossRef]

26. Xu, Y.; Zhang, X.; Tian, Y.; Chen, C.; Nan, Y.; He, H.; Wang, M. Study on the nucleation and growth of $\mathrm{M}_{23} \mathrm{C}_{6}$ carbides in a 10\% $\mathrm{Cr}$ martensite ferritic steel after long-term aging. Mater. Charact. 2016, 111, 122-127. [CrossRef]

27. Hou, Z.; Hedstrom, P.; Chen, Q.; Xu, Y.; Wu, D.; Odqvist, J. Quantitative modeling and experimental verification of carbide precipitation in a martensitic Fe- $0.16 \mathrm{wt} \% \mathrm{C}-4.0 \mathrm{wt} \% \mathrm{Cr}$ alloy. Calphad 2016, 53, 39-48. [CrossRef]

28. Jeong, J.; Lee, C.Y.; Park, I.J.; Lee, Y.K. Isothermal precipitation behavior of kappa-carbide in the Fe-9Mn-6Al-0.15C lightweight steel with a multiphase microstructure. J. Alloy. Compd. 2013, 574, 299-304. [CrossRef]

29. Jang, K.N.; Kim, T.K.; Kim, K.T. The effect of cooling rates on carbide precipitate and microstructure of 9CR-1MO oxide dispersion strengthened (ODS) steel. Nucl. Eng. Technol. 2018, in press. [CrossRef]

30. Morsdorf, L.; Tasan, C.C.; Ponge, D.; Raabe, D. 3D structural and atomic-scale analysis of lath martensite: Effect of the transformation sequence. Acta Mater. 2015, 95, 366-377. [CrossRef]

31. Dollar, M.; Bernstein, I.M.; Thompson, A.W. Influence of deformation substructure on flow and fracture of fully pearlitic steel. Acta Metall. 1988, 36, 311-320. [CrossRef]

32. Ray, K.K.; Mondal, D. The effect of interlamellar spacing on strength of pearlite in annealed eutectoid and hypoeutectoid plain carbon steels. Acta Metall. Mater. 1991, 39, 2201-2208. [CrossRef]

33. Modi, O.P.; Deshmukh, N.; Mondal, D.P.; Jha, A.K.; Yegneswaran, A.H.; Khaira, H.K. Effect of interlamellar spacing on the mechanical properties of $0.65 \%$ C steel. Mater. Charact. 2001, 46, 347-352. [CrossRef]

34. Shibanuma, K.; Nemoto, Y.; Hiraide, T.; Suzuki, K.; Sadamatsu, S.; Adachi, Y.; Aihara, S. A strategy to predict the fracture toughness of steels with a banded ferrite-pearlite structure based on the micromechanics of brittle fracture initiation. Acta Mater. 2018, 144, 386-399. [CrossRef]

35. Hall, E.O. The deformation and ageing of mild steel: III Discussion of results. Proc. Phys. Soc. Sect. 1951, B64, 747-753. [CrossRef]

36. Petch, N.J. The cleavage strength of polycrystals. J. Iron Steel Inst. 1953, 174, 25-28.

37. Victor, K. Modes of Fracture. In ASM Metals Handbook; Robert, L.S., Ed.; ASM International: Materials Park, $\mathrm{OH}, \mathrm{USA}, 1992$; Volume 12, p. 35.

(C) 2018 by the authors. Licensee MDPI, Basel, Switzerland. This article is an open access article distributed under the terms and conditions of the Creative Commons Attribution (CC BY) license (http:/ / creativecommons.org/licenses/by/4.0/). 